\title{
Distribution of Catalytic Species as an Indicator to Overcome Reproducibility Problems
}

DOI:

10.1021/jacs.7b05045

\section{Document Version}

Accepted author manuscript

Link to publication record in Manchester Research Explorer

\section{Citation for published version (APA):}

Companyo, X., \& Bures Amat, J. (2017). Distribution of Catalytic Species as an Indicator to Overcome

Reproducibility Problems. Journal of the American Chemical Society. https://doi.org/10.1021/jacs.7b05045

\section{Published in:}

Journal of the American Chemical Society

\section{Citing this paper}

Please note that where the full-text provided on Manchester Research Explorer is the Author Accepted Manuscript or Proof version this may differ from the final Published version. If citing, it is advised that you check and use the publisher's definitive version.

\section{General rights}

Copyright and moral rights for the publications made accessible in the Research Explorer are retained by the authors and/or other copyright owners and it is a condition of accessing publications that users recognise and abide by the legal requirements associated with these rights.

\section{Takedown policy}

If you believe that this document breaches copyright please refer to the University of Manchester's Takedown Procedures [http://man.ac.uk/04Y6Bo] or contact uml.scholarlycommunications@manchester.ac.uk providing relevant details, so we can investigate your claim.

\section{OPEN ACCESS}


This document is confidential and is proprietary to the American Chemical Society and its authors. Do not copy or disclose without written permission. If you have received this item in error, notify the sender and delete all copies.

\section{Distribution of Catalytic Species as an Indicator to Overcome Reproducibility Problems}

\begin{tabular}{|r|l|}
\hline Journal: & Journal of the American Chemical Society \\
\hline Manuscript ID & ja-2017-050455.R1 \\
\hline Manuscript Type: & Communication \\
\hline Date Submitted by the Author: & $10-J u n-2017$ \\
\hline Complete List of Authors: & $\begin{array}{l}\text { Companyó, Xavier; Universita degli studi di Padova Scuola di Scienze, } \\
\text { Burés, Jordi; University of Manchester School of Chemistry }\end{array}$ \\
\hline
\end{tabular}

\section{SCHOLARONE' \\ Manuscripts}


The reproducibility of catalytic reactions is rarely tested in the early stages of their development, but it can be an obstacle for their broad application later on. Capricious catalytic reactions are avoided in key synthetic steps and industrial applications regardless of their performance in yield, selectivity, mildness, cost or significance of the products. The common way to minimize irreproducibility is by ensuring enhanced control over the reaction factors that might contribute to generate it, such as impurities, temperature or stirring rates. However, this strategy might fail for factors that are difficult to measure and/or change during the course of the reaction. Herein we present the distribution of catalytic species as a new indicator to evaluate catalyst performance in situ, and its use in overcoming irreproducibility.

In catalytic reactions, the kinetic constants and the concentration of reactants, impurities and additives determine the rate of the reaction as well as the distribution of catalytic species. Usually, the distribution of catalytic species is ignored, or at most used to infer mechanistic information. We propose to use it as an indicator of the rate of reactions where the control and measurement of reaction parameters is difficult (Figure 1).

\begin{abstract}
Irreproducibility is a common issue in catalysis. The ordinary way to minimize it is by ensuring enhanced control over the factors that affect the reaction. When conof the reaction performance. Herein we describe the use of the distribution of catalytic species as an indicator to map, track and fine-tune the performance of catalytic reactions. This indicator is very sensitive and presents a quick response new strategy to the conjugate addition of C-nucleophiles to enals via iminium intermediates, consistently achieving maximum turnover frequencies (TOF) regardless of the qualmethod has allowed us to efficiently reduce the catalyst loading to as little as $0.1 \mathrm{~mol} \%$, the lowest one described for this kind of reaction.
\end{abstract}

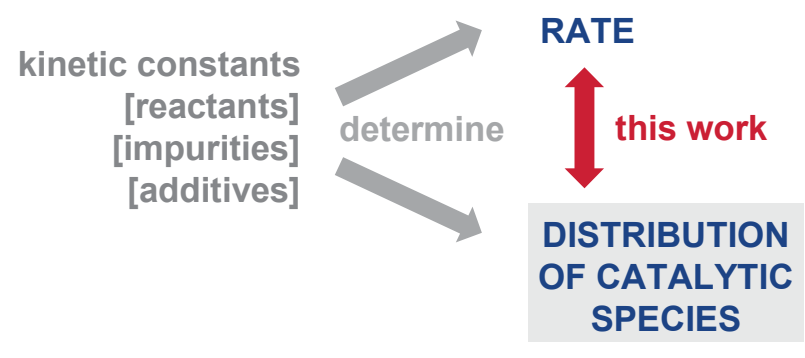

Figure 1. The distribution of catalytic species is a good indicator of the rate of the reaction when the control of reaction parameters is difficult.

To show the power of this new indicator, we have chosen the aminocatalytic Michael addition of $C$-nucleophiles to conjugated aldehydes. Although it is one of the benchmark reactions operating via iminium activation mode, there are important discrepancies in the literature evincing reproducibility problems. Concretely, similar reactions have been reported to perform better in the presence of acid as an additive, ${ }^{1}$ base as an additive ${ }^{2}$ and in the absence of additives. ${ }^{3}$ The benefits of each additive can be justified from a mechanistic point of view due to the interconnected catalytic network of these reactions (Scheme 1).

Scheme 1. General mechanism for the conjugate addition of nucleophiles to enals via iminium intermediates.

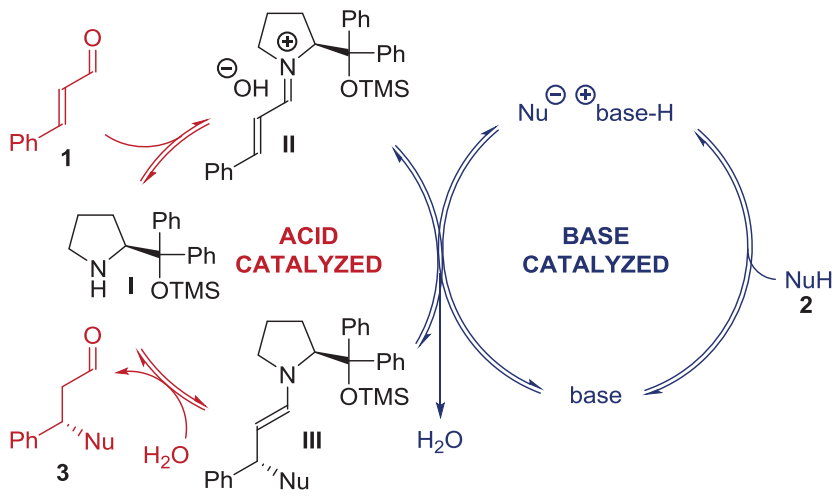


a)

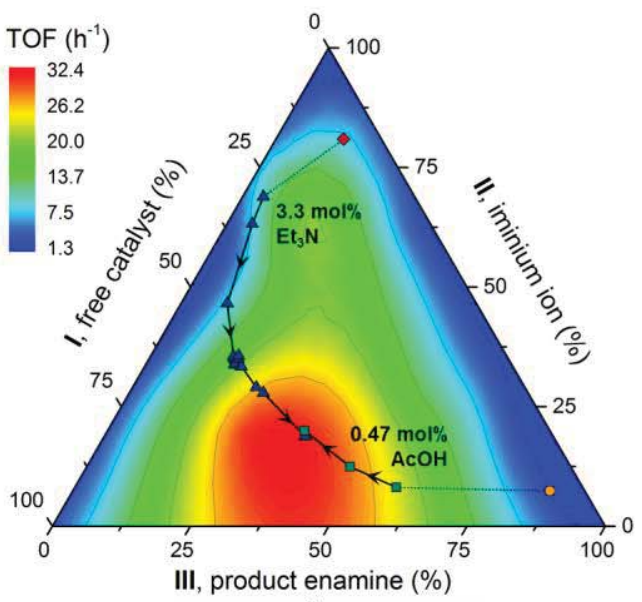

b)

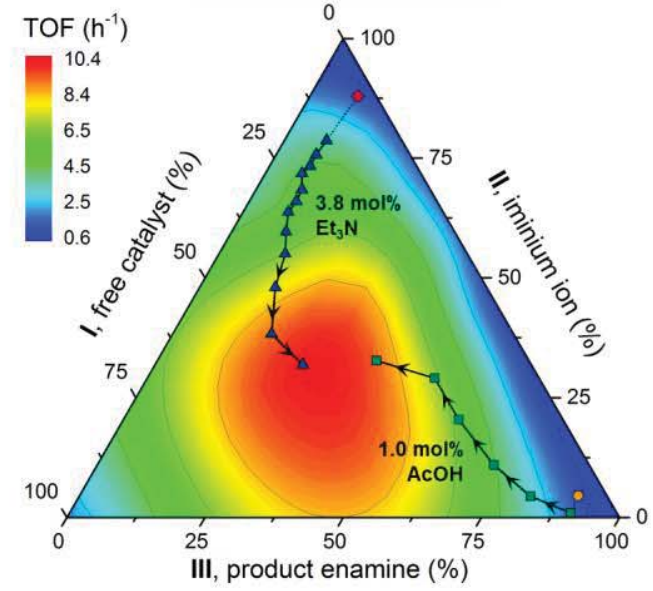

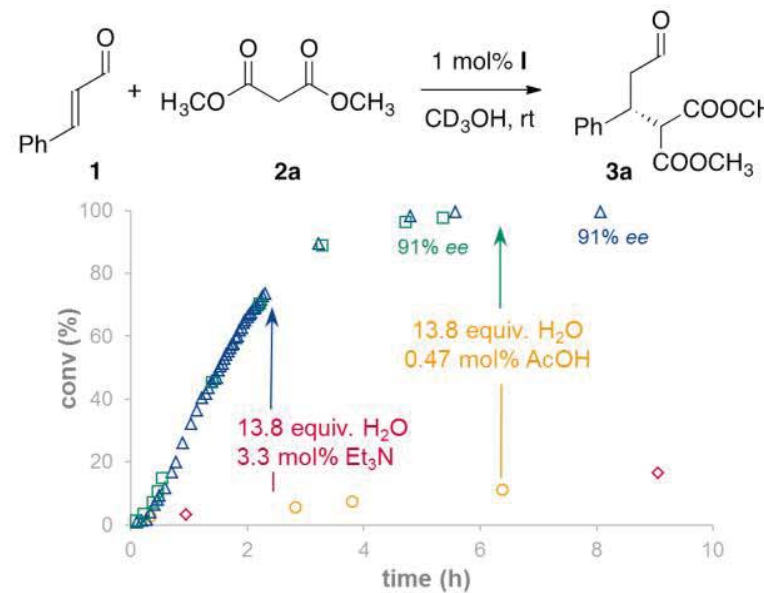

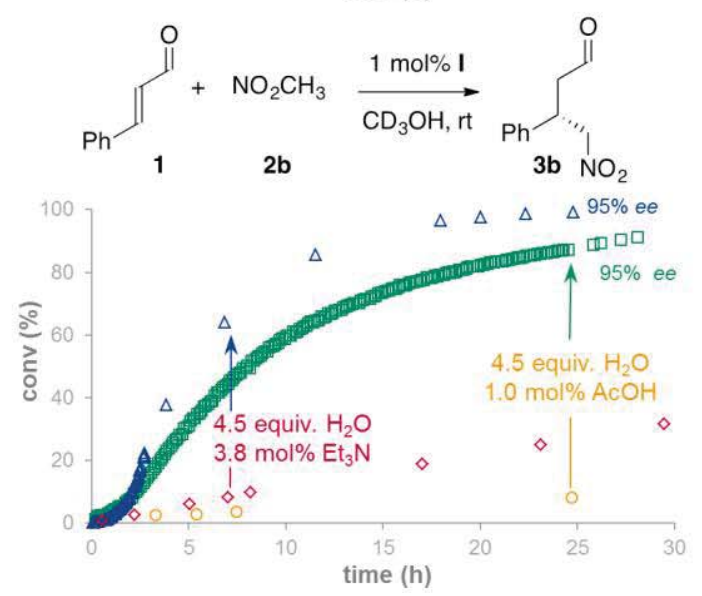

Figure 2. Map-assisted reaction optimization from different cinnamaldehyde (1) batches leading to similar optimized reaction profiles with (a) dimethyl malonate (2a) and (b) nitromethane (2b). ${ }^{6}$

The overall reaction involves two fused catalytic cycles sharing one step and therefore both cycles have to turn over at the same rate, like the gears of a clock. One of the cycles limits the rate of the other one and it determines the overall reaction kinetics. In addition, most of the steps drawn in the mechanism involve several proton-transfer processes, and therefore their rates are extremely sensitive to the acidity of the reaction media. Basic additives accelerate the cycle in blue (Scheme 1 right), but inhibit the steps in red (Scheme 1 left), which are known to be accelerated in acid conditions. ${ }^{4}$ The fine balance of all the steps makes these reactions especially sensitive to acidic impurities, usually contained in aldehydes, $^{5}$ and bases, as the aminocatalyst itself. Therefore, the reaction requires different additives depending on the quantity of acid contained in each batch of aldehyde and on the catalyst loading used. Careful distillation of the aldehyde reduces the content of acid, but it does not provide a sufficiently consistent amount to guarantee reproducibility. When high catalyst loadings are used, these traces of acid are neutralized by the catalyst itself, mitigating its perturbing effect. However, its presence becomes critical with low amounts of catalyst, and high variability in the reaction rate is observed.

As any other reaction indicator, the distribution of catalytic species needs to be calibrated. To do so, the distribution of catalytic species and the rate of the reaction were measured simultaneously under a range of reaction conditions by NMR. ${ }^{6}$ This information was then graphically summarized in ternary contour plots. We used ternary contour plots because we were able to quantify three main catalytic species: free catalyst I, iminium of the starting enal $\mathbf{~ I I}^{7}$ and product enamine III (Scheme 1). ${ }^{8}$ Each position of the ternary plot correlates with a unique distribution of catalytic species and the colored contours indicate the turnover frequency of the reaction. During this process, we discovered that extra water was necessary to achieve optimal TOF, but the most critical and sensitive parameter was the acidity of the media.

Figure 2a shows the fine-tuning of the addition of dimethyl malonate (2a) to cinnamaldehyde (1) catalyzed by only 1 mol\% of diphenyl prolinol trimethylsilyl ether I for two very different batches of cinnamaldehyde. The first reaction was set up with undistilled cinnamaldehyde. The initial distribution of catalytic species was I:II:III=7:81:12 (Figure za left, red diamond). The large proportion of iminium ion II indicates that the C-C bond forming step is limiting the rate of the overall reaction and therefore a basic additive should increase the TOF of the reaction. Consequently, we adjusted the amount of water and added triethylamine until we observed the optimal distribution of catalytic species (red zone of the ternary plot). Several consecutive small amounts of triethylamine were added to show the shift of the distribution of catalytic species (Figure za left, blue triangles). Using this information, the correct amount of additive could be estimated based on the original distribution of catalytic species and, in practice, one single addition was enough to achieve the optimal reaction conditions. The corrected reac- 
tion with only $1 \mathrm{~mol} \%$ proved to be much quicker than the original reaction, reaching full conversion in $5 \mathrm{~h}$ with the same enantioselectivity as the original reaction (Figure $2 \mathrm{a}$ right). The second reaction was set up with a batch of freshly distilled cinnamaldehyde (Figure za left, yellow circle). The initial distribution of catalytic species was I:II:III=5:5:90. The large proportion of product enamine III indicates that the final hydrolysis step is limiting the rate of the overall reaction and in this case acid should accelerate the reaction. We were delighted to observe that upon the addition of water and acid, the distribution of catalytic species shifted to the red zone of the plot (Figure za left, green squares). As in the previous case, the reaction was much faster than the original reaction and the enantioselectivity of the reaction was preserved (Figure za right). More importantly, both optimized reactions from very different batches of aldehyde had similar kinetic profiles. The reactions consistently resulted in more than $90 \%$ conversion in around $3 \mathrm{~h}$ using only $1 \mathrm{~mol} \%$ of catalyst, which represents an average TOF between $c a$. 10 to 30o-fold higher than the pioneering works run at o ${ }^{\circ} \mathrm{C}^{1 \mathrm{~d}, 2 \mathrm{e}, 3 \mathrm{~d}}$

We also successfully applied the method to the asymmetric conjugate addition of nitromethane (2b) to cinnamaldehyde (1) catalyzed by $\mathbf{I}^{1 \mathrm{e}, 1 \mathrm{f}, 2 \mathrm{~d}}$ As in the previous case, the distribution of catalytic species guided us to decide the quantity and the nature of the best additive for each batch of cinnamaldehyde (Figure $2 \mathrm{~b}$ left). Again, the reactions consistently performed better than the previously reported cases (average TOF of $3.4 \mathrm{~h}^{-1}$ compared to 0.17 to $\left.0.1 \mathrm{~h}^{-1}\right) .^{1,1 \mathrm{f}, 2 \mathrm{~d}}$

The contour plots created with 1 mol\% were used to finetune reactions with other catalyst loadings. The reduction of catalyst loading entails an obvious reduction in reaction rate, but due to its basic nature, it also affects the acidity of the media. This change in the acidity of the media also changes the quantity and even the nature of the best additive for the reaction. Figure za shows the optimization of three reactions run with the same batch of starting materials, but with 10, 1 and $0.1 \mathrm{~mol} \%$ of catalyst (I). The initial distributions of catalytic species appeared in very different areas of the plot, revealing the impact of the catalyst concentration on the acidity of the reaction media. With $10 \mathrm{~mol} \%$ (Figure za, red diamonds) and $1 \mathrm{~mol} \%$ (Figure 3a, blue triangles) of catalyst, different amounts of acid were needed as an additive to achieve the optimal distribution of catalytic species. In the case of $0.1 \mathrm{~mol} \%$ of catalyst (Figure 3a, green squares), base was required to achieve a similar distribution of catalytic species. The two reactions using 10 and $1 \mathrm{~mol} \%$ of catalyst were completed in $30 \mathrm{~min}$ and $5 \mathrm{~h}$ respectively, ${ }^{6}$ but the reaction with $0.1 \mathrm{~mol} \%$ required further corrections during the reaction time in order to maintain the optimal distribution of catalytic species. We believe these corrections were necessary to compensate very small amounts of acid produced during the course of the reaction (Figure $3 b-d) .^{5 a}$ These repeated corrections were only needed when using 0.1 mol\% of catalyst, where the catalytic system was extremely sensitive to any acidity variation of the media. The completion of the reaction with only $0.1 \mathrm{~mol} \%$ of a JørgensenHayashi type catalyst ${ }^{9}$ is the lowest one described until now. This accomplishment evidences that the use of this kind of catalyst was not limited by high degrees of deactivation ${ }^{6,10}$ nor insufficient TOF, but by the lack of control of the reaction conditions. With proper reaction control and without reproducibility issues, this kind of catalysts should be competitive in industrial process. ${ }^{11}$

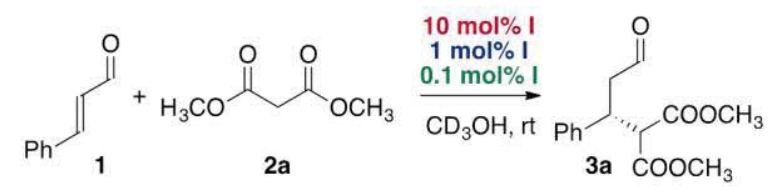

a)

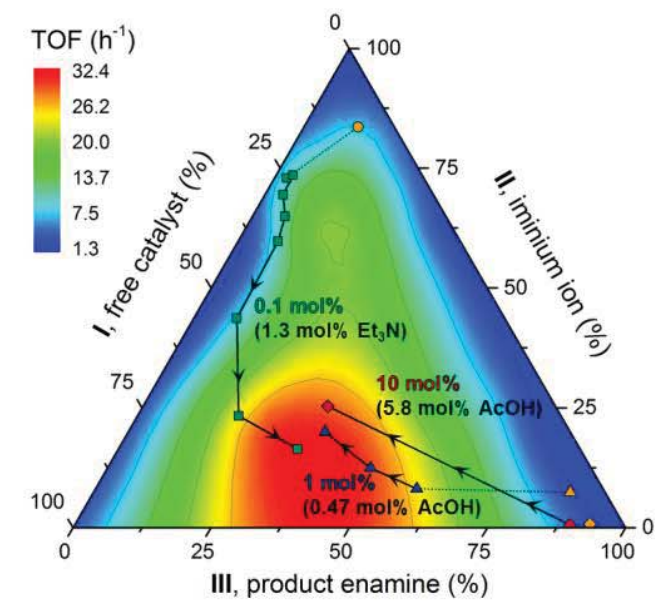

b)

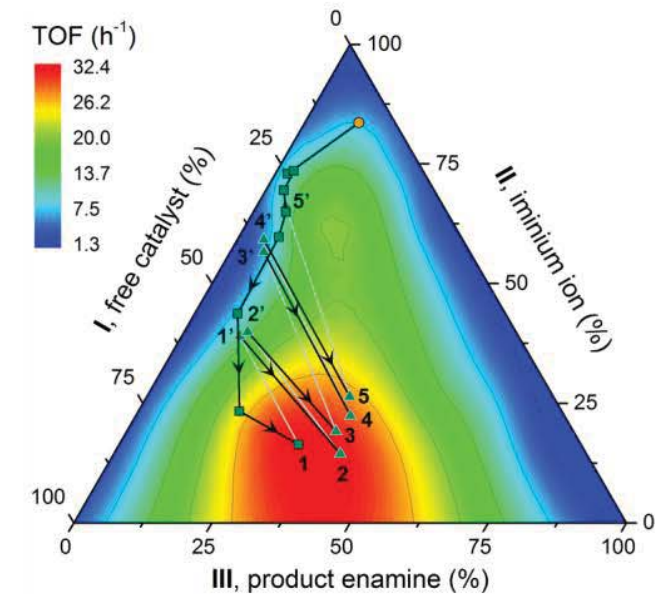

c)

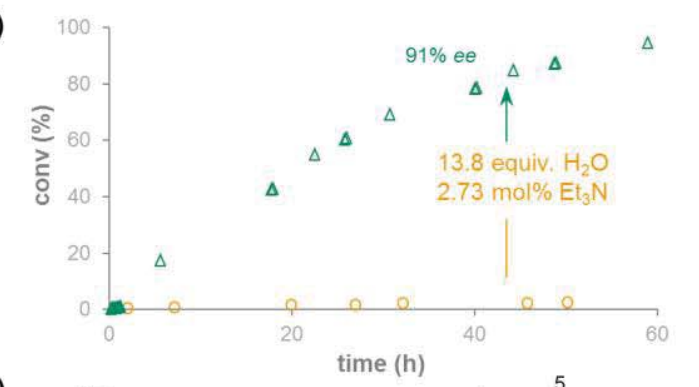

d)

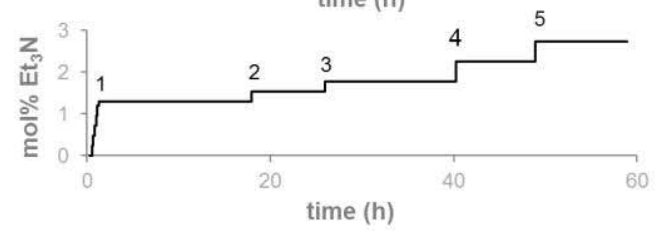

Figure 3. (a) Effect of the catalyst loading over the distribution of catalytic species. (b) Confining the distribution of catalytic species in the maximum TOF area at $0.1 \mathrm{~mol} \%$ of catalyst loading (c) Kinetic profile of the fine-tuned (green) and blank (yellow) reactions at $0.1 \mathrm{~mol} \%$ of catalyst loading. (d) $\mathrm{Et}_{3} \mathrm{~N}$ addition profile. ${ }^{6}$ 
This last example proves the utility of the method herein described. If the reaction had been optimized using 1 or 10 mol\%, acid would have been incorrectly employed as additive also for the reaction with $0.1 \mathrm{~mol} \%$ of catalyst. Even if the reaction with $0.1 \mathrm{~mol} \%$ had been optimized independently, a single addition of base would have been insufficient to complete the reaction. In both scenarios, the conclusion would have been that the reaction cannot be completed with such a small amount of catalyst.

Finally, in order to prove the potential of the method beyond NMR scale, we applied it in a gram-scale reaction with nondeuterated solvent (Figure 4). We run a reaction with 5 mmol of dimethyl malonate $\mathbf{2 a}, 10 \mathrm{mmol}$ of undistilled cinnamaldehyde $\mathbf{1}$, and $1 \mathrm{~mol} \%$ of catalyst $\mathbf{I}$ in ACS grade methanol. The distribution of catalytic species was measured by no-D NMR ${ }^{12}$ of an aliquot of the reaction. The correct additive and its amount were decided as described previously (Figure 4, green triangles). Then, the proportional amount of triethylamine was added to the main batch of the reaction and it was confirmed that the distribution of catalytic species was the expected one (Figure 4, blue square). Without further modification, the reaction reached full conversion in 4 $\mathrm{h}$, affording $1.16 \mathrm{~g}$ of the Michael adduct $3 \mathrm{a}(80 \%$ isolated yield) with $92 \% e e^{6}$

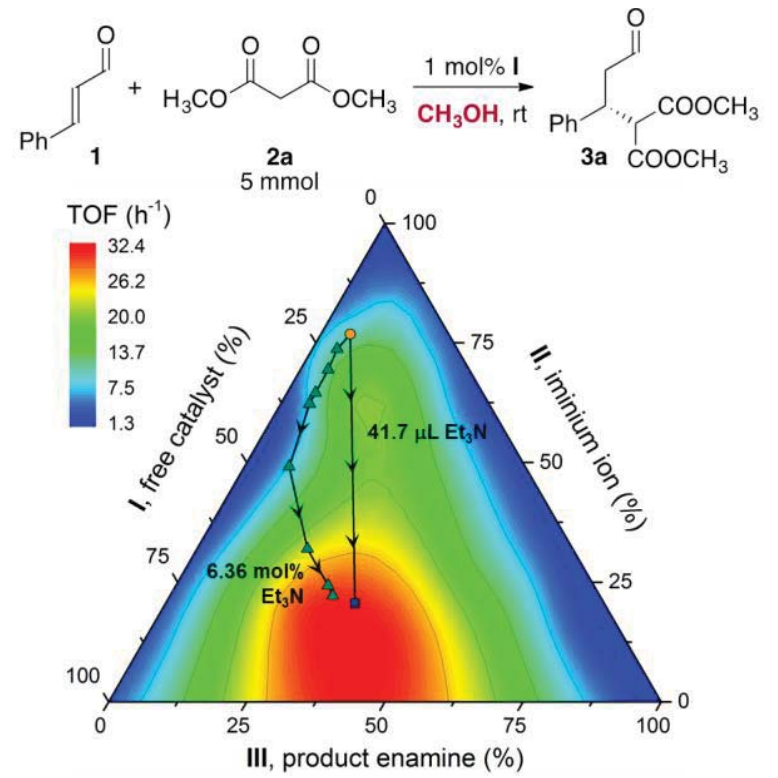

Figure 4. Gram-scale reaction with non-deuterated $\mathrm{MeOH}{ }^{6}$

The method herein presented can be used regardless of the analytical technique chosen to measure the distribution of catalytic intermediates. Therefore, this method can also be implemented in reactions impossible to monitor by NMR.

In summary, we have used the distribution of catalytic species as a new indicator to quickly evaluate and in situ optimize the performance of a catalyst. We have exemplified the utility of this approach in the conjugate addition of Cnucleophiles to enals under iminium activation. This method is able to overcome the problems related to variation in reaction conditions, therefore solving discrepancies in the literature. This new indicator has allowed the reduction of the catalyst loading to as little as $0.1 \mathrm{~mol} \%$ for the addition of dimethyl malonate to cinnamaldehyde.

\section{ASSOCIATED CONTENT}

\section{Supporting Information}

The Supporting Information is available free of charge on the ACS Publications website. Characterization of the catalytic species and kinetic profiles by NMR; experimental procedure for the construction of the ternary contour maps and for the map-assisted reaction optimization.

\section{AUTHOR INFORMATION}

\section{Corresponding Author}

jordi.bures@manchester.ac.uk

\section{Notes}

The authors declare no competing financial interests.

\section{ACKNOWLEDGMENT}

The research leading to these results has received funding from the European Union $\mathrm{FP}_{7} / 2007-2013$ under grant agreement $n^{0}$ PCIG 13-GA-2013-618589 (J.B.) and PIEF-GA-2013627895 (X.C.), from the IC JRF scheme (J.B.), and from The University of Manchester (J.B.).

\section{REFERENCES}

1. (a) Choi, K.-S.; Kim, S.-G. Eur. J. Org. Chem. 2012, 1119; (b) Fleischer, I.; Pfaltz, A. Chem. Eur. J. 2010, 16, 95; (c) Zhang, S.; Zhang, Y.; Ji, Y.; Li, H.; Wang, W. Chem. Commun. 2009, 4886; (d) Landa, A.; Puente, A.; Santos, J. I.; Vera, S.; Oiarbide, M.; Palomo, C. Chem. Eur. J. 2009, 15, 11954; (e) Gotoh, H.; Ishikawa, H.; Hayashi, Y. Org. Lett. 2007, 9, 5307; (f) Zu, L.; Xie, H.; Li, H.; Wang, J.; Wang, W. Adv. Synth. Catal. 2007, 349, 2660.

2. (a) Heo, S.; Kim, S.; Kim, S.-G. Tetrahedron Lett. 2013, 54, 4978; (b) Garcia Ruano, J. L.; Marcos, V.; Aleman, J. Chem. Commun. 2009, 4435; (c) Ullah, F.; Zhao, G. L.; Deiana, L.; Zhu, M.; Dziedzic, P.; Ibrahem, I.; Hammar, P.; Sun, J.; Cordova, A. Chem. Eur. J. 2009, 15, 10013; (d) Wang, Y.; Li, P.; Liang, X.; Zhang, T. Y.; Ye, J. Chem. Commun. 2008, 1232; (e) Wang, Y.; Li, P.; Liang, X.; Ye, J. Adv. Synth. Catal. 2008, 350, 1383.

3. (a) Lee, Y; Seo, S. W.; Kim, S.-G. Adv. Synth. Catal. 2011, 353 , 2671; (b) Alba, A. N.; Companyó, X.; Moyano, A.; Rios, R. Chem. Eur. J. 2009, 15, 11095; (c) Alba, A. N.; Companyó, X.; Moyano, A.; Rios, R. Chem. Eur. J. 2009, 15, 7035; (d) Brandau, S.; Landa, A.; Franzen, J.; Marigo, M.; Jørgensen, K. A. Angew. Chem. Int. Ed. 20o6, 45, 4305.

4. (a) Gotoh, H.; Uchimaru, T.; Hayashi, Y. Chem. Eur. J. 2015, 21, 12337; (b) Burés, J.; Armstrong, A.; Blackmond, D. G. Chemical Science 2012, 3, 1273; (c) Burés, J.; Armstrong, A.; Blackmond, D. G. J. Am. Chem. Soc. 2012, 134, 6741; (d) Burés, J.; Armstrong, A.; Blackmond, D. G. J. Am. Chem. Soc. 2011, 133, 8822.

5. (a) Heidlindemann, M.; Berkessel, A.; Gröger, H. ChemCatChem 2017, 9, 1383; (b) Shapiro, N.; Vigalok, A. Angew. Chem. Int. Ed. 2oo8, 47, 2849.

6. See Supporting Information.

7. (a) Brazier, J. B.; Jones, K. M.; Platts, J. A. Tomkinson N. C. O. Angew. Chem. Int. Ed. 2011, 5o, 1613; (b) Evans, G.; Gibbs, T. J. K.; Jenkins, R. L.; Coles, S. J.; Hursthouse M. B.; Platts J. A.; Tomkinson N. C. O. Angew. Chem. Int. Ed. 2008, 47, 2820; (c) Lakhdar, S.; Tokuyasu T.; Mayr H. Angew. Chem. Int. Ed. 2oo8, 47, 8723.

8. (a) Schmid, M. B.; Zeitler, K.; Gschwind R. M. J. Am. Chem. Soc. 2011, 133, 7065; (b) Schmid, M. B.; Zeitler, K.; Gschwind R. M. Angew. Chem. Int. Ed. 2010, 49, 4997.

9. Donslund, B. S.; Johansen, T. K.; Poulsen, P. H.; Halskov, K. S.; Jørgensen, K. A. Angew. Chem. Int. Ed. 2015, 54, 13860.

10. Haindl, M. H.; Schmid, M. B.; Zeitler, K.; Gschwind, R. M. RSC Adv. 2012, 2, 5941.

11. Giacalone, F.; Gruttadauria, M.; Agrigento, P.; Noto, R. Chem. Soc. Rev. 2012, 41, 2406.

12. Hoye, T. R.; Eklov, B. M.; Ryba, T. D.; Voloshin, M.; Yao, L. J. Org. Lett. 2004, 6, 953. 


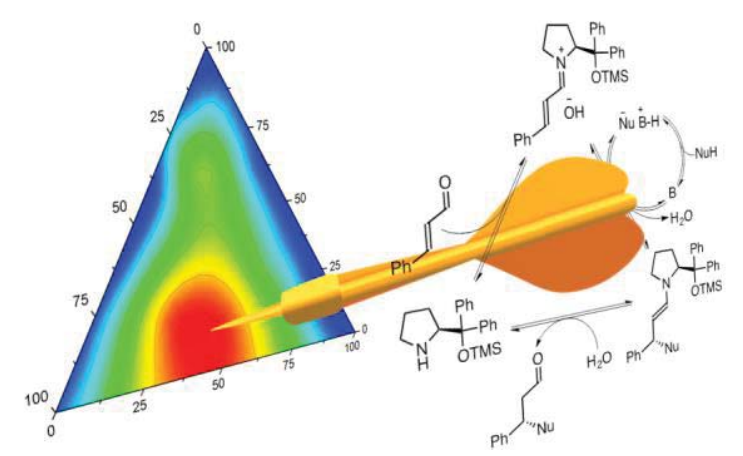


Figure 1. The distribution of catalytic species is a good indicator of the rate of the reaction when the control of reaction parameters is difficult.

\section{$84 \times 39 \mathrm{~mm}(300 \times 300 \mathrm{DPI})$}


a)

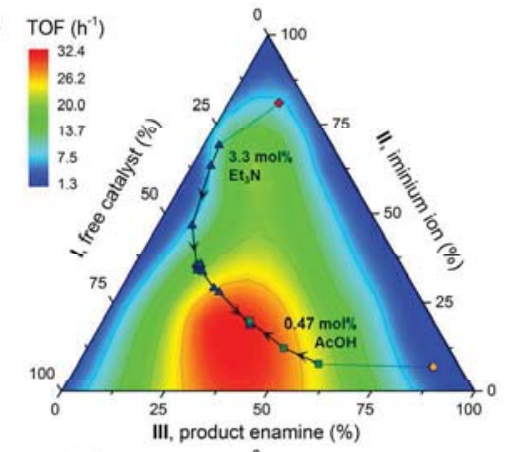

b)

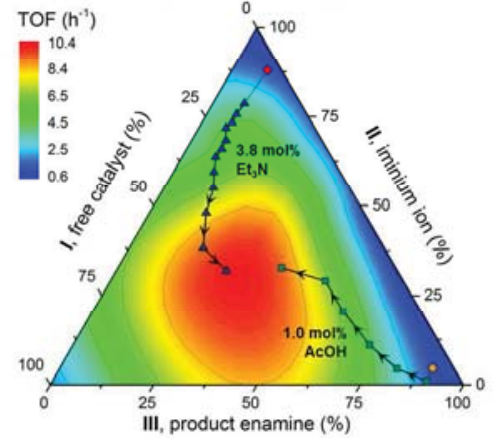

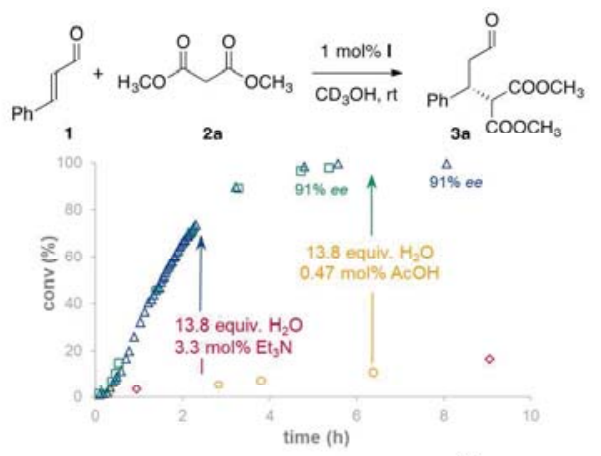
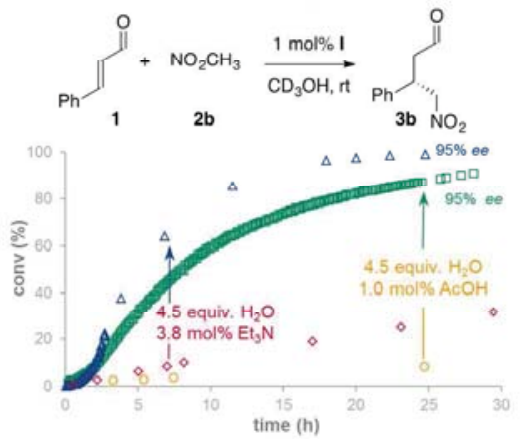

Figure 2. Map-assisted reaction optimization from different cinnamaldehyde (1) batches leading to similar optimized reaction profiles with (a) dimethyl malonate (2a) and (b) nitromethane (2b).6

$176 \times 119 \mathrm{~mm}$ ( $300 \times 300$ DPI) 
Figure 3. (a) Effect of the catalyst loading over the distribution of catalytic species. (b) Confining the distribution of catalytic species in the maximum TOF area at $0.1 \mathrm{~mol} \%$ of catalyst loading (c) Kinetic profile of the fine-tuned (green) and blank (yellow) reactions at $0.1 \mathrm{~mol} \%$ of catalyst loading. (d) Et3N addition profile. 6

$$
84 \times 204 \mathrm{~mm}(300 \times 300 \text { DPI })
$$




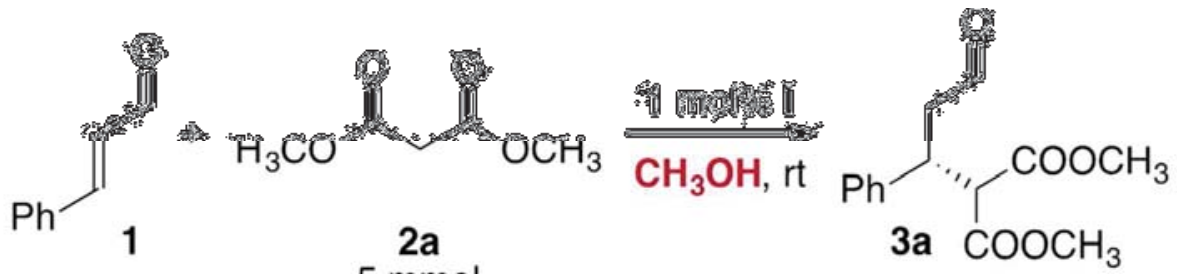

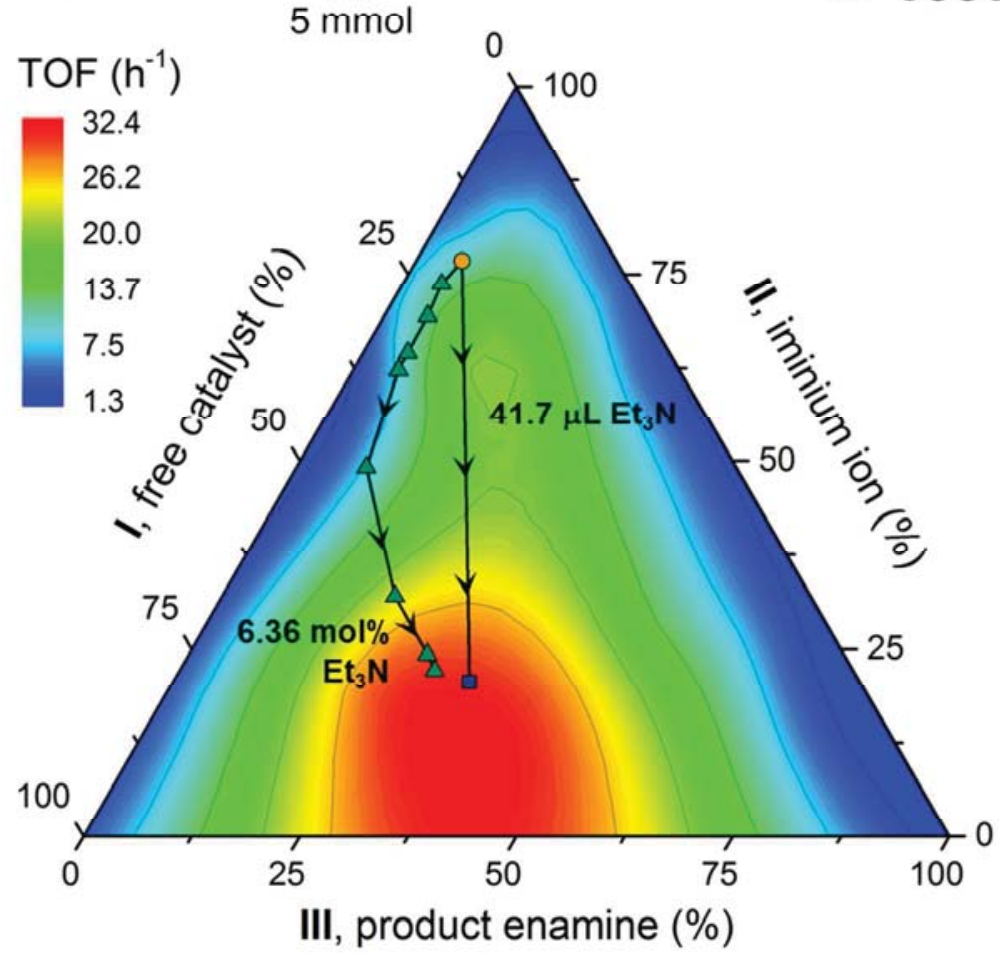

Figure 4. Gram-scale reaction with non-deuterated MeOH.6 $84 \times 77 \mathrm{~mm}(300 \times 300 \mathrm{DPI})$ 


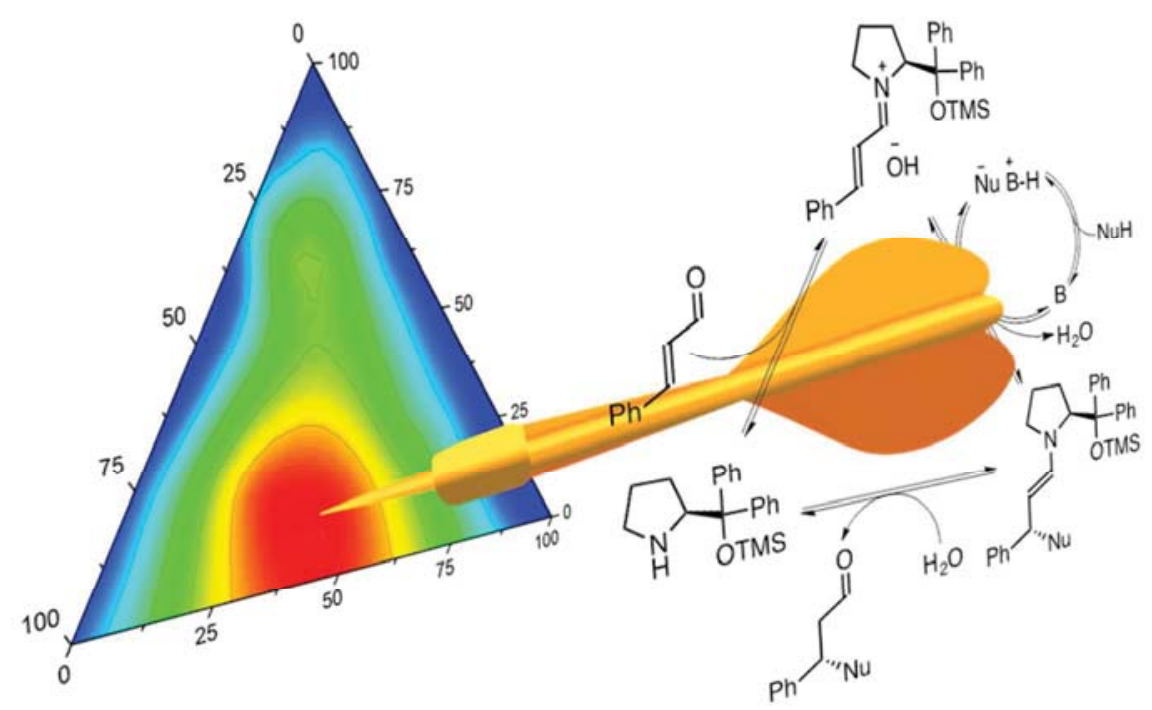

$82 \times 44 \mathrm{~mm}(300 \times 300$ DPI $)$ 